\title{
RACIAL INEQUALITY AND SEGREGATION MEASURES: SOME EVIDENCE FROM THE 2000 CENSUS
}

\author{
Rajiv Sethi \\ Email: rs328@columbia.edu \\ Department of Economics \\ Barnard College \\ Columbia University and the Institute for Advanced Study
}

\author{
Rohini Somanathan \\ Email: rohini@econdse.org \\ Department of Economics \\ Delhi School of Economics \\ University of Delhi
}

Working Paper No. 177 


\title{
Racial Inequality and Segregation Measures: Some Evidence from the 2000 Census*
}

\author{
Rajiv Sethi ${ }^{\dagger} \quad$ Rohini Somanathan ${ }^{\ddagger}$
}

April 9, 2009

\begin{abstract}
How much of the observed segregation between black and white Americans can be attributed to income disparities between the two groups? We adopt an approach to the decomposition of segregation measures that combines the method of indirect standardization with the idea that some degree of segregation is the outcome of purely random processes. Using the dissimilarity index as a measure of segregation and data on race and income from US metropolitan areas for 2000 , we find that the role played by racial income inequality in accounting for segregation is modest but varies significantly across cities. Our work suggests that for cities that are relatively small or for those where the share of black households in the total population is small, it may be useful to adjust existing measures of dissimilarity to better capture the role of non-income factors in determining segregation.
\end{abstract}

Keywords: Residential Segregation, Racial Income Disparities, Dissimilarity Index.

\footnotetext{
${ }^{*}$ For comments on an earlier version we thank Dan O'Flaherty and an anonymous referee.

${ }^{\dagger}$ Department of Economics, Barnard College, Columbia University and the Institute for Advanced Study (rs328@columbia.edu).

${ }^{\ddagger}$ Department of Economics, Delhi School of Economics (rohini@econdse.org).
} 


\section{Introduction}

The historical persistence of residential segregation has been widely discussed (Massey and Denton 1993, Farley and Frey 1994, Cutler et al. 1999, Glaeser and Vigdor 2001). African-American households experience levels of segregation that far exceed those of other groups, especially in the older cities of the Northeast and Midwest. The two metropolitan areas with the largest black populations, New York and Chicago, had black-white indexes of dissimilarity exceeding 80 in the year 2000, and similar levels of black-white separation continue to prevail in Detroit, Newark and Milwaukee.

The existence of segregation has been attributed to some combination of neighborhood preferences, discrimination in real estate and credit markets, and the effect of racial disparities in income and wealth. While there has been lively debate on the relative importance of preferences and discrimination in housing markets, there appears to be a broad consensus that racial income disparities are a relatively unimportant factor in accounting for existing patterns of segregation. This argument has been based on the finding that the levels of segregation experienced by black households are uniformly high across all income categories (Denton and Massey 1988, Farley and Frey 1994) and on results from the indirect standardization approach which we describe below. Farley et al. (1994) go so far as to say that the "the economic explanation has largely been jettisoned." 1

We revisit the question of how much segregation can be accounted for by racial income disparities by combining the method of indirect standardization (Duncan et al., 1961, Massey 1981) with the idea that some degree of segregation is the outcome of purely random processes. The indirect standardization approach quantifies the degree of segregation that would occur if households sorted themselves based on income alone. This is done by using as a benchmark a hypothetical city in which each neighborhood has the same number of households in each income category as the actual city, but the racial composition within each income category of each neighborhood is assumed to equal the city-wide racial composition in that category. The difference in segregation between the actual and hypothetical city provides a measure of the role of racial inequality in explaining segregation.

As pointed out by Cortese et al. (1976), if household location decisions are influenced by idiosyncratic factors unrelated to income or race, segregation, as measured by the dissimilarity index, would be exaggerated. The exaggeration may be significant if city neighborhoods or minority populations are small. We modify the indirect standardization method based on this idea. Rather than construct a hypothetical city in which the racial composition within each income class is identical

\footnotetext{
${ }^{1}$ See also Kain (1976), Galster (1988), McKinney and Schnare (1989) and Ellen (2000) on the relative unimportance of income disparities in accounting for observed levels of segregation. The idea the relatively moderate preferences over neighborhood racial composition can give rise to extreme levels of segregation when households make decentralized location choices was developed in the influential work of Schelling (1971); Clark (1991) argues for the continuing relevance of the Schelling model. Evidence on racial steering in housing markets and differential access to mortgage credit in accounting for segregation may be found, for instance, in Yinger (1995).
} 
across all neighborhoods, we assume only that it is drawn from the same distribution and therefore has the city racial composition as its expected value. Measured segregation in the hypothetical city now reflects sorting based on both income and idiosyncratic neighborhood preferences and the difference between the segregation index for the actual and hypothetical city can then be interpreted as the component of segregation that cannot be accounted for by either income considerations or random factors. Racial imbalances across neighborhoods arising due to such randomness can be large if the share of either the black or white population in particular income groups is small. We discuss this in greater detail below in the context of the 2000 census.

Applying this method to data on neighborhood income distributions by race for metropolitan areas in the 2000 census, we find that the role played by racial income disparities in accounting for segregation is generally modest but varies significantly across cities. Using census tracts as neighborhood units and focusing on the segregation of African Americans from non-Hispanic whites, we find that racial income disparities and randomness alone would predict indexes of dissimilarity ranging from 0.04 to 0.30 , with an unweighted average of 0.10 . This is far lower than the observed dissimilarity indexes which range from 0.26 to 0.85 with an average of 0.54 , confirming the widelyheld view that observed levels of black-white segregation are largely due to factors other than racial disparities in income. We do however find considerable variation across cities in the extent to which income matters. The proportion of the observed index that can be attributed to income disparities and randomness ranges from $7 \%$ to $46 \%$, with an average of $19 \%$. Segregation rankings based on the residual index (obtained by subtracting the actual from the expected hypothetical index) can look quite different from rankings based on the original index. As might be expected, metropolitan areas with fewer households and a small percentage of African Americans are the ones for which allowing for randomness makes the most difference.

We divide our set of 331 cities into four categories based on whether they are above or below median size and whether the share of African American households in total households is above or below the median share. We find that for the first category (below median size and below median black share) $23 \%$ of the observed segregation can be attributed to racial income disparities and randomness in household location whereas for the group of cities with above median population and black share, the corresponding figure is $16 \%$. We also find that the share explained by these factors is greatest in states in the West, and smallest in those in the Northeast.

The following section describes our methods in more detail and Section ?? applies these to data from the 2000 census. We conclude with a few summary remarks.

\section{Method}

Consider a metropolitan area with $n$ disjoint neighborhoods. Let $B$ denote the population of black households in the city and $W$ the total population of (non-Hispanic) white households. In neighborhood $i$ the population of black and white households are denoted $B_{i}$ and $W_{i}$ respectively. 
A variety of segregation measures can be constructed based on the racial composition of the city's neighborhoods (Duncan and Duncan, 1955). Although our general approach can be applied to any of these, we focus here on the index of dissimilarity which has an interpretation as the proportion of black (or white) households which must move in order for each neighborhood to have the same racial composition as the city as a whole. The index is defined as:

$$
D=\frac{1}{2} \sum_{i=1}^{n}\left|\frac{B_{i}}{B}-\frac{W_{i}}{W}\right| .
$$

and varies between zero (all neighborhoods mirror the black-white shares of the city) and 1 (racially homogeneous neighborhoods). Since the index does not incorporate any information on income, high levels of dissimilarity are therefore consistent with households sorting themselves across neighborhoods based on income alone. To investigate the role of racial income disparities in explaining observed segregation, once could examine segregation indices by income group, or use a summary measure obtained by the method of indirect standardization (Duncan et al., 1961, Massey 1981). We first describe this method and then proceed to our proposed modification.

Suppose that there are $m$ distinct income classes. Let $B_{i j}$ and $W_{i j}$ denote the number of black and white households respectively residing in neighborhood $i$ and income class $j . B_{j}$ and $W_{j}$ are city-wide aggregates and $\beta_{j}$ and $\omega_{j}$ refer to the city-wide shares of the two groups. The method of indirect standardization keeps constant the total population in each income class of each neighborhood, but alters the racial composition within each income class to match that of the city as a whole. Using an asterisk to denote populations in the hypothetical city, we have

$$
\begin{aligned}
B_{i j}^{*} & =\beta_{j}\left(B_{i j}+W_{i j}\right), \\
W_{i j}^{*} & =\omega_{j}\left(B_{i j}+W_{i j}\right) .
\end{aligned}
$$

Total black and white households in neighborhood $i$ of the hypothetical city are, respectively, $B_{i}^{*}=\sum_{j=1}^{m} B_{i j}^{*}$ and $W_{i}^{*}=\sum_{j=1}^{m} W_{i j}^{*}$. These magnitudes can then be used to compute an index of dissimilarity for the hypothetical city, namely

$$
D_{h}=\frac{1}{2} \sum_{i=1}^{n}\left|\frac{B_{i}^{*}}{B}-\frac{W_{i}^{*}}{W}\right| .
$$

If segregation by race was purely an unintended by-product of socioeconomic stratification, then $D_{h}$ and $D$ would be equal. If, on the other hand, households sort themselves based on both income and race (or characteristics correlated with race), $D$ will exceed $D_{h}$.

Figure 1 shows actual and hypothetical city data for New York County (Manhattan), with neighborhoods corresponding to census block groups. ${ }^{2}$ Despite significant racial disparities in the

\footnotetext{
${ }^{2}$ The hypothetical city is constructed using data from all eight counties in the New York PMSA, although only Manhattan is depicted.
} 
distribution of income, the black population is spread far more evenly across the hypothetical city. ${ }^{3}$ The areas with relatively large black populations in the hypothetical city are precisely those with low average incomes. Neighborhoods that are poor but predominantly white in the actual city are disproportionately black in the hypothetical city. The racial composition of the hypothetical city therefore provides a visual description of the spatial distribution of income.

It has sometimes been argued that the benchmark against which the dissimilarity index should be compared is not the perfectly even distribution which results in a zero value of the index, but rather the expected value of the index when each neighborhood is occupied by individuals drawn randomly from the population of the city (Cortese et al., 1976). For the standard dissimilarity index, this expected value turns out to be negligible, especially in larger cities with sizeable black populations (Massey, 1978). However, with the method of indirect standardization described above, allowing for randomness could have significant effects because even in metropolitan areas in which the share of the minority population is quite large, there could be income groups in which it is small.

\section{Insert Figure 1 about here}

Figure 1. Segregation in Manhattan: Actual and Hypothetical

We allow for randomness in a straightforward manner. Let $T_{j k}$ denote the total (black plus nonHispanic white) population in income class $j$ within neighborhood $k$. Then the number of black households in this income class of this neighborhood is obtained by random draw from a binomial distribution with total trials $T_{j k}$ and probability of success $\beta_{j}$. This is done for each income class and neighborhood to generate a single random hypothetical city, for which the dissimilarity index can be computed. The process is repeated a large number of times to generate a sample of dissimilarity indexes for the city. We found that 100 repetitions were enough to generate a closely clustered distribution. The mean of this sample, denoted $\bar{D}_{h}$, is then an unbiased estimator of the expected value of the dissimilarity index with random assignment of individuals to neighborhoods within each income class. In the next section we present these means for different U.S. metropolitan areas.

For most major cities with significant black populations, the difference between $D_{h}$ and $\bar{D}_{h}$, turns out to be negligible. There do exist metropolitan areas, however, for which the difference is large. For the complete sample of 331 metropolitan areas, the following table summarizes our findings:

\footnotetext{
${ }^{3}$ For evidence on the extent of racial income disparities in the New York metropolitan area, see the estimates below of $\beta_{i}$ (the share of black households in each of the sixteen income classes).
} 


\begin{tabular}{|l|c|c|c|c|}
\hline & Mean & S.D. & Min & Max \\
\hline$D$ & 0.54 & 0.12 & 0.26 & 0.85 \\
\hline$D_{h}$ & 0.07 & 0.03 & 0.01 & 0.15 \\
\hline $\bar{D}_{h}$ & 0.10 & 0.03 & 0.04 & 0.30 \\
\hline
\end{tabular}

The fraction $\bar{D}_{h} / D$, interpreted as the proportion of $D$ than can be attributed to income differences and random factors, ranges from $7 \%$ to $45 \%$ nationwide. We explore the determinants of this fraction in more detail in Section ?? below.

Let $D_{r}=D-\bar{D}_{h}$ denote the residual component of the dissimilarity index. This can be interpreted as the amount of segregation which cannot be accounted for by racial income disparities and idiosyncratic factors alone. Like the index of dissimilarity, $D_{r}$ cannot exceed 1 . However, unlike $D$, it is theoretically possible for it to be negative. Negative values would reflect strongly integrationist attitudes reflecting a mutual preference for living with members of the other group over one's own. As we show below, empirical estimates of $D_{r}$ are significantly greater than zero in all the major metropolitan areas of the United States.

As an example, consider the case of the New York PMSA, which is composed of the five counties comprising New York City together with three adjoining counties. Data from the 2000 census are available for sixteen income classes, and can be used to compute the share of black households within each income class for the city as a whole. ${ }^{4}$ Doing this, we get:

\begin{tabular}{|c|c|c|c|c|c|c|c|c|c|c|c|c|c|c|c|}
\hline$\beta_{1}$ & $\beta_{2}$ & $\beta_{3}$ & $\beta_{4}$ & $\beta_{5}$ & $\beta_{6}$ & $\beta_{7}$ & $\beta_{8}$ & $\beta_{9}$ & $\beta_{10}$ & $\beta_{11}$ & $\beta_{12}$ & $\beta_{13}$ & $\beta_{14}$ & $\beta_{15}$ & $\beta_{16}$ \\
\hline 0.53 & 0.40 & 0.40 & 0.35 & 0.33 & 0.30 & 0.26 & 0.23 & 0.22 & 0.17 & 0.13 & 0.11 & 0.07 & 0.06 & 0.04 & 0.03 \\
\hline
\end{tabular}

Black households are overrepresented in lower income groups and underrepresented at the top of the income distribution. To the extent that neighborhoods are shared by individuals with roughly comparable income, this would result in some degree of segregation by race. Setting $\omega_{j}=1-\beta_{j}$ and applying (??-??), we can construct the hypothetical city and compute the level of segregation $D_{h}$ that would be observed there. Allowing for randomness, in the manner described above, we can create a sample of such cities and compute the mean level of segregation $\overline{D_{h}}$ in the sample. Results obtained for New York are as follows, where $s\left(D_{h}\right), \min \left(D_{h}\right)$, and $\max \left(D_{h}\right)$ are the standard deviation, minimum and maximum of the sample of a hundred randomly generated cities.

\begin{tabular}{|c|c|c|c|c|c|}
\hline$D$ & $D_{h}$ & $\bar{D}_{h}$ & $s\left(D_{h}\right)$ & $\min \left(D_{h}\right)$ & $\max \left(D_{h}\right)$ \\
\hline 0.818 & 0.110 & 0.113 & 0.001 & 0.112 & 0.115 \\
\hline
\end{tabular}

Two facts are apparent: allowing for randomness has a negligible effect in a city of this size and diversity, and a very small portion of the level of segregation can be attributed to racial income disparities. The reason is not that racial income inequality is low, but rather that "the degree of

\footnotetext{
${ }^{4}$ The values of $\beta_{i}$ in the table refer to the black share of total black plus non-Hispanic white households, excluding members of other groups.
} 
residential segregation between socioeconomic classes is not particularly impressive" (Massey, 1981, p.645).

\section{Data}

The 2000 Census provides data on household income distribution by race at the level of census tracts. ${ }^{5}$ There are sixteen income classes in all. Some cities are part of vast consolidated metropolitan areas (CMSAs) containing multiple nuclei; such areas are further divided into Primary Metropolitan Statistical Areas (PMSAs) each of which can be identified with a single nucleus. For instance Newark and New York belong to different PMSAs but are both part of the same vast CMSA which includes significant portions of New York, New Jersey and Connecticut. In selecting the geographic boundaries of metropolitan areas, we have chosen to include only those counties which are part of the PMSA to which the city of interest belongs.

We begin by reporting, in Table 1, results for the thirty metropolitan areas with the largest number of black households in $2000 .{ }^{6}$ In terms of the overall level of segregation our findings are consistent with those reported in other studies (Glaeser and Vigdor, 2001). ${ }^{7}$ Overall, we find that racial income disparities account for relatively little of the observed segregation. If segregation were based on socioeconomic stratification alone one would obtain dissimilarity indices ranging from 0.06 in Fort Lauderdale to 0.14 in Newark, with an average for the thirty cities of 0.11. In contrast, observed values of $D$, which range from 0.44 in Raleigh to 0.85 in Detroit, with an average of 0.66 in this sample. Nevertheless, we find substantial variation across cities in the extent to which income matters. In Fort Lauderdale only one-tenth of the dissimilarity index can be attributed to income disparities; in Raleigh the corresponding figure is almost one-fourth. There are six metropolitan areas in which $\bar{D}_{h}$ accounts for one-fifth of total segregation or more: Dallas, Houston, Memphis, Norfolk, Oakland, Raleigh and Richmond. Five of the six are in the South, and none are in the North-East or Midwest where the highest levels of segregation currently prevail. This suggests that there may be systematic regional variation in the extent to which segregation can be attributed to

\footnotetext{
${ }^{5}$ Much of the literature on segregation uses census tracts rather than block groups, and we follow this tradition. Note, however, that tracts that seem integrated can be composed of blocks that are themselves racially homogenous. For instance, Ellen (2000, p.78) finds that about a third of the block groups in a sample of integrated Washington D.C. census tracts are either predominantly black or predominantly white (integrated tracts are defined as those in which the black share of the total population is between 10 and 50 percent).

${ }^{6}$ This facilitates comparison with Massey and Denton (1993), who focus on the thirty areas with the largest black populations in 1990. Due to changes in population sizes and area definitions, only 24 of the 30 areas on their list appear in ours. Buffalo, Columbus, Gary, Milwaukee, Pittsburgh and San Francisco have been replaced by Charlotte, Fort Lauderdale, Jacksonville, Oakland, Raleigh and Richmond.

${ }^{7}$ Income distributions by race are available at the census tract level only for households, and only in the STF3 data set. Most segregation studies use STF1 data on persons, so conformity with our results cannot be exact. Our use of STF3 data also introduces sampling error into our estimates, but given the large number of households in each metropolitan area we expect this to be negligible.
} 
racial income inequality.

Table 1. Components of Segregation for 30 cities with the largest black populations

\begin{tabular}{|c|c|c|c|c|c|c|c|}
\hline MSA/PMSA & Households & Black & White & $D$ & $\bar{D}_{h}$ & $D_{r}$ & $\bar{D}_{h} / D$ \\
\hline Atlanta & $1,504,871$ & $28 \%$ & $64 \%$ & 0.63 & 0.10 & 0.53 & $16 \%$ \\
\hline Baltimore & 974,071 & $26 \%$ & $69 \%$ & 0.67 & 0.12 & 0.55 & $18 \%$ \\
\hline Birmingham & 361,304 & $28 \%$ & $69 \%$ & 0.70 & 0.12 & 0.58 & $17 \%$ \\
\hline Boston & $1,323,186$ & $6 \%$ & $84 \%$ & 0.67 & 0.09 & 0.58 & $14 \%$ \\
\hline Charlotte-Gastonia-Rock Hill & 575,293 & $19 \%$ & $75 \%$ & 0.53 & 0.09 & 0.44 & $17 \%$ \\
\hline Chicago & $2,971,690$ & $18 \%$ & $66 \%$ & 0.79 & 0.12 & 0.67 & $15 \%$ \\
\hline Cincinnati & 645,048 & $13 \%$ & $84 \%$ & 0.75 & 0.12 & 0.63 & $16 \%$ \\
\hline Cleveland-Lorain-Elyria & 892,562 & $18 \%$ & $78 \%$ & 0.78 & 0.11 & 0.67 & $15 \%$ \\
\hline Dallas & $1,281,957$ & $15 \%$ & $64 \%$ & 0.59 & 0.13 & 0.46 & $21 \%$ \\
\hline Detroit & $1,695,331$ & $21 \%$ & $73 \%$ & 0.85 & 0.10 & 0.75 & $12 \%$ \\
\hline Fort Lauderdale & 654,445 & $16 \%$ & $67 \%$ & 0.60 & 0.06 & 0.54 & $10 \%$ \\
\hline Greensboro-Winston Salem-High Point & 498,751 & $19 \%$ & $76 \%$ & 0.56 & 0.07 & 0.49 & $12 \%$ \\
\hline Houston & $1,462,663$ & $18 \%$ & $54 \%$ & 0.66 & 0.13 & 0.53 & $20 \%$ \\
\hline Indianapolis & 629,655 & $13 \%$ & $83 \%$ & 0.71 & 0.09 & 0.62 & $13 \%$ \\
\hline Jacksonville & 425,584 & $20 \%$ & $74 \%$ & 0.54 & 0.09 & 0.45 & $16 \%$ \\
\hline Kansas City & 694,467 & $12 \%$ & $81 \%$ & 0.70 & 0.11 & 0.59 & $16 \%$ \\
\hline Los Angeles-Long Beach & $3,133,774$ & $11 \%$ & $43 \%$ & 0.68 & 0.10 & 0.58 & $15 \%$ \\
\hline Memphis & 424,202 & $40 \%$ & $57 \%$ & 0.67 & 0.13 & 0.53 & $20 \%$ \\
\hline Miami & 776,765 & $18 \%$ & $24 \%$ & 0.71 & 0.12 & 0.59 & $17 \%$ \\
\hline New Orleans & 505,579 & $34 \%$ & $60 \%$ & 0.68 & 0.12 & 0.56 & $17 \%$ \\
\hline New York & $3,484,103$ & $23 \%$ & $47 \%$ & 0.82 & 0.11 & 0.70 & $14 \%$ \\
\hline Newark & 729,062 & $21 \%$ & $63 \%$ & 0.80 & 0.14 & 0.66 & $17 \%$ \\
\hline Norfolk-Virginia Beach-Newport News & 577,659 & $29 \%$ & $65 \%$ & 0.48 & 0.10 & 0.37 & $22 \%$ \\
\hline Oakland & 867,495 & $13 \%$ & $57 \%$ & 0.62 & 0.12 & 0.50 & $20 \%$ \\
\hline Philadelphia & $1,914,245$ & $19 \%$ & $73 \%$ & 0.73 & 0.12 & 0.60 & $17 \%$ \\
\hline Raleigh-Durham-Chapel Hill & 461,097 & $22 \%$ & $71 \%$ & 0.44 & 0.10 & 0.34 & $23 \%$ \\
\hline Richmond-Petersburg & 387,721 & $28 \%$ & $67 \%$ & 0.56 & 0.11 & 0.45 & $20 \%$ \\
\hline St. Louis & $1,012,418$ & $17 \%$ & $80 \%$ & 0.73 & 0.11 & 0.62 & $15 \%$ \\
\hline Tampa-St. Petersburg-Clearwater & $1,009,316$ & $9 \%$ & $81 \%$ & 0.64 & 0.07 & 0.57 & $11 \%$ \\
\hline Washington DC & $1,848,061$ & $26 \%$ & $61 \%$ & 0.63 & 0.11 & 0.52 & $18 \%$ \\
\hline
\end{tabular}


Table 2. Components of Segregation for 20 cities with highest segregation levels.

\begin{tabular}{|l|r|c|c|c|c|c|c|}
\hline MSA/PMSA & Households & Black & White & $D$ & $\bar{D}_{h}$ & $D_{r}$ & $\bar{D}_{h} / D$ \\
\hline Detroit, MI & $1,695,331$ & $21 \%$ & $73 \%$ & 0.85 & 0.10 & 0.75 & $12 \%$ \\
\hline Gary, IN & 236,282 & $19 \%$ & $71 \%$ & 0.84 & 0.10 & 0.74 & $12 \%$ \\
\hline Milwaukee-Waukesha, WI & 587,657 & $14 \%$ & $80 \%$ & 0.83 & 0.15 & 0.68 & $18 \%$ \\
\hline New York, NY & $3,484,103$ & $23 \%$ & $47 \%$ & 0.82 & 0.11 & 0.70 & $14 \%$ \\
\hline Newark, NJ & 729,062 & $21 \%$ & $63 \%$ & 0.80 & 0.14 & 0.66 & $17 \%$ \\
\hline Chicago, IL & $2,971,690$ & $18 \%$ & $66 \%$ & 0.79 & 0.12 & 0.67 & $15 \%$ \\
\hline Cleveland-Lorain-Elyria, OH & 892,562 & $18 \%$ & $78 \%$ & 0.78 & 0.11 & 0.67 & $15 \%$ \\
\hline Buffalo-Niagara Falls, NY & 468719 & $11 \%$ & $84 \%$ & 0.78 & 0.12 & 0.66 & $15 \%$ \\
\hline Saginaw-Bay City-Midland MI & 156129 & $9 \%$ & $86 \%$ & 0.77 & 0.08 & 0.68 & $11 \%$ \\
\hline Flint MI & 169825 & $19 \%$ & $77 \%$ & 0.76 & 0.09 & 0.68 & $11 \%$ \\
\hline Johnstown PA & 91753 & $1 \%$ & $98 \%$ & 0.75 & 0.10 & 0.65 & $14 \%$ \\
\hline Cincinnati, OH-KY-IN & 645,048 & $13 \%$ & $84 \%$ & 0.75 & 0.12 & 0.63 & $16 \%$ \\
\hline Benton Harbor MI & 63569 & $14 \%$ & $82 \%$ & 0.74 & 0.09 & 0.65 & $12 \%$ \\
\hline Nassau-Suffolk, NY & 916686 & $7 \%$ & $82 \%$ & 0.74 & 0.05 & 0.69 & $7 \%$ \\
\hline Provo-Orem UT & 99937 & $0.2 \%$ & $92 \%$ & 0.74 & 0.24 & 0.49 & $33 \%$ \\
\hline Fort Wayne IN & 192052 & $7 \%$ & $89 \%$ & 0.73 & 0.08 & 0.65 & $12 \%$ \\
\hline St. Louis MO-IL & $1,012,418$ & $17 \%$ & $80 \%$ & 0.73 & 0.11 & 0.62 & $15 \%$ \\
\hline Syracuse, NY & 282600 & $6 \%$ & $90 \%$ & 0.73 & 0.12 & 0.61 & $16 \%$ \\
\hline Philadelphia PA-NJ & $1,914,245$ & $19 \%$ & $73 \%$ & 0.73 & 0.12 & 0.60 & $17 \%$ \\
\hline Bergen-Passaic NJ & 494673 & $7 \%$ & $72 \%$ & 0.73 & 0.09 & 0.64 & $12 \%$ \\
\hline
\end{tabular}

Table 2 shows results for the 20 metropolitan areas that were the most segregated according to the dissimilarity index in 2000. Again, we find that racial income disparities play at most a minor role in accounting of segregation, with the sole exception of Provo-Orem in Utah. This metropolitan area has a negligible black population, however, and it may be that much of the observed segregation can be attributed to random chance. For the remaining areas, hypothetical city segregation levels range from 0.05 in Nassau-Suffolk (Long Island) to 0.15 in Milwaukee. The average for the twenty cities is just 0.11 , even with the inclusion of the outlier. The actual dissimilarity index ranges from 0.73 in Bergen-Passaic to 0.85 in Detroit, averaging 0.77. As before, there is some geographic variation in the proportion of $D$ that is explained by $\bar{D}_{h}$. Excluding Provo, this ranges from $7 \%$ in Nassau-Suffolk to $18 \%$ in Milwaukee. This variation implies that certain area may be ranked quite differently depending on whether $D$ or $D_{r}$ is used. For instance Philadelphia is ranked 19th according to the standard measure but drops to 31st under the adjusted measure, while Long Island rises from 14 th to 4 th. 
For most cities in Tables 1 and 2, we find that $\bar{D}_{h}$ does not differ substantially from the simpler measure $D_{h}$ and neither of these comes close to approximating observed levels of segregation $D$. Segregation in these cases can therefore reasonably be attributed to non-income factors. This is much less true for cities that are small in terms of their total populations and have fewer African American households. We divide our 331 MSAs into four categories based on whether the population share of black households (among all black plus white households) is above or below the median share of $7.5 \%$, and whether the total number of black plus white households is above or below the median value of 95,752 households. The percentage of total segregation explained by $\bar{D}_{h}$ is $23 \%$ in small cities with small black shares; this is much larger than corresponding figures for other categories of cities.

Table 3: Percentage $\bar{D}_{h} / D$ for different categories of MSAs

\begin{tabular}{|l|c|c|}
\hline & Low Black Share & High Black Share \\
\hline Small Total Population & $23 \%$ & $17 \%$ \\
\hline Large Total Population & $18 \%$ & $16 \%$ \\
\hline
\end{tabular}

These results are not surprising since a small number of neighborhoods in a city makes it relatively more difficult for households to sort by both income and race. Income sorting is therefore likely to be more important than in larger cities. Also, given city size, a small number of black households is likely to lead to greater racial imbalance through purely random processes.

We also find that modifying the indirect standardization approach by allowing for some randomness in household location makes the most difference for cities that are both small in size and have small black shares. For this category, average segregation in the hypothetical city without allowing for random location is 0.05 , whereas the mean value of $\bar{D}_{h}$ is about double this at 0.11 . For the remaining categories of cities (which have above median population sizes and/or above median black shares) randomness plays a negligible role and one may reasonably conclude that levels of hypothetical city segregation $\bar{D}_{h}$ reflect racial income disparities and sorting by income. For this latter class of cities, Table 4 displays variation by census region. ${ }^{8}$

Table 4: Percentage $\bar{D}_{h} / D$ by region (excluding small and racially homogeneous MSAs)

\begin{tabular}{|c|c|c|c|}
\hline Northeast & Midwest & South & West \\
\hline $15 \%$ & $17 \%$ & $17 \%$ & $20 \%$ \\
\hline
\end{tabular}

Although differences across regions are minor, it does appear that economic factors explain more of the observed segregation in Western states, especially in comparison with states in the Northeast.

\footnotetext{
${ }^{8} \mathrm{~A}$ few MSAs span two census regions; these are assigned to the region in which the majority of the population resides.
} 


\section{Conclusions}

We have examined the extent to which income differences across racial groups can account for observed residential segregation, building on the indirect standardization approach by allowing for some randomness in the allocation of households across neighborhoods. Our decomposition is based on the comparison of observed segregation with the segregation that would occur in a hypothetical city which is identical in the number and size of neighborhoods but where the city share of each race determines the probability of a household being allocated to a given neighborhood.

Since our approach generates a hypothetical allocation, it could be used with any of the standard segregation measures. We focus on the dissimilarity index in our analysis of data from U.S. metropolitan areas in 2000 simply because this is the measure most frequently used in the literature. Our findings suggest that contemporary levels of segregation are not driven by sorting across neighborhoods on the basis of household income. We note, however, that racial disparities in accumulated physical and financial assets are significantly greater than those in income (Oliver and Shapiro, 1997). To the extent that stratification by wealth exceeds stratification by income in metropolitan areas, our results will understate the importance of economic disparities in accounting for segregation.

The noneconomic component of the dissimilarity index expresses the combined effects on segregation of neighborhood preferences, discrimination and other factors unrelated to racial income disparities. Use of our decomposition does not permit one to distinguish among these determinants. Our finding that the effect of racial income disparities on contemporary levels of segregation is modest does, however, underscore the importance of examining preferences and discrimination. It also provides a straightforward method of assessing the extent to which narrowing racial income disparities have played a role in recent declines in segregation, and in the increasing stability of integrated neighborhoods in certain areas (Cutler et al., 1999, Ellen, 2000).

While racial disparities in the distribution of income may be a relatively unimportant factor in accounting for existing segregation, our analysis shows that there is sufficient variability across cities in the contribution of this factor to warrant further exploration. When interpreting differences across cities in levels of segregation, it is important to take account structural and economic factors that may cause one city to have higher levels of segregation than another, even if preferences over neighborhood racial composition were identical. Our analysis suggests that such comparisons are reasonable if cities are either sufficiently large or are sufficiently heterogeneous with respect to their racial composition. We also find that economic inequality can account for a somewhat greater proportion of segregation in Western states. Segregation in the Northeast, in comparison, is driven by largely noneconomic factors.

We expect that the role of racial economic inequality as a determinant of segregation will increase over time. Farley and Frey (1994), for instance, predict a "stronger link between the economic status of blacks and integration" as the institutionalized segregation of the Jim Crow 
laws recedes further into the past. By keeping track of the separate components of segregation, such predictions can be empirically tested as new data become available. 


\section{References}

[1] Adelman, Robert M. (2004). "Neighborhood Opportunities, Race, and Class: The Black Middle Class and Residential Segregation." City and Community 3: 43-63.

[2] Clark, W.A.V. (1991). "Residential Preferences and Neighborhood Racial Segregation: A Test of the Schelling Segregation Model." Demography 28: 1-19.

[3] Cortese, C.F., R.F. Falk and J.K. Cohen (1976). "Further Considerations on the Methodological Analysis of Segregation Indices." American Sociological Review 41: 630-637.

[4] Cutler, D.M., E.L. Glaeser and J.L. Vigdor (1999). "The Rise and Decline of the American Ghetto." Journal of Political Economy 107: 455-506.

[5] Denton, N.A. and D.S. Massey (1988). "Residential Segregation of Blacks, Hispanics and Asians by Socioeconomic Status and Generation." Social Science Quarterly 69: 797-817.

[6] Duncan, O.D. and B. Duncan (1955). "A Methodological Analysis of Segregation Indexes", American Sociological Review, 20: 210-217.

[7] Duncan, O.D., R.P. Cuzzort, and B. Duncan (1961). Statistical Geography: Problems of Analyzing Areal Data. New York: Glencoe.

[8] Ellen, I.G. (2000). Sharing America's Neighborhoods: The Prospects for Stable Racial Integration. Cambridge: Harvard University Press.

[9] Farley, R., C. Steeh, M. Krysan, T. Jackson, and K. Reeves (1994). "Stereotypes and Segregation: Neighborhoods in the Detroit Area." American Journal of Sociology 100: 750-780.

[10] Farley, R. and W.H. Frey (1994). "Changes in the Segregation of Whites from Blacks during the 1980: Small Steps toward a more Integrated Society." American Sociological Review 59: $23-45$.

[11] Fischer, Mary J. (2003). "The Relative Importance of Income and Race in Determining Residential Outcomes in U.S. Urban Areas, 1970-2000." Urban Affairs Review 38: 669-96.

[12] Galster, G. (1988). "Residential Segregation in American Cities: A Contrary View." Population Research and Policy Review 7: 93-112.

[13] Glaeser, E.L. and J.L. Vigdor (2001). "Racial Segregation in the 2000 Census: Promising News." The Brookings Institution Survey Series, April: 1-16.

[14] Iceland, John, Sharpe Cicely, and Erika Steinmetz (2005). "Class Differences in African American Residential Patterns in U.S. Metropolitan Areas: 1990-2000." Social Science Research 34: $252-66$. 
[15] Kain, J.F. (1976). "Race, Ethnicity, and Residential Location." In Public and Urban Economics, edited by R. Grieson. Lexington: Lexington Books.

[16] Massey D.S. (1978). "On the Measurement of Segregation as a Random Variable." American Sociological Review 43: 587-590.

[17] Massey D.S. (1981). "Social Class and Ethnic Segregation: A Reconsideration of Methods and Conclusions." American Sociological Review 46: 641-650.

[18] Massey, D.S. and N.A. Denton (1993). American Apartheid: Segregation and the Making of the Underclass. Cambridge: Harvard University Press.

[19] McKinney, S. and A.B. Schnare (1989). "Trends in Residential Segregation by Race, 19601980." Journal of Urban Economics 26: 269-280.

[20] Oliver, M.L. and T.M. Shapiro (1997). Black Wealth/White Wealth: A New Perspective of Racial Inequality. New York: Routledge.

[21] Schelling, T.C. (1971). "Dynamic Models of Segregation." Journal of Mathematical Sociology 1: $143-86$.

[22] Sethi, Rajiv and Rohini Somanathan. 2004. "Inequality and Segregation." Journal of Political Economy, 112:6, pp. 1296-1321.

[23] U.S. Census Bureau (1999). Metropolitan Areas with Components, 1990 with FIPS codes (on line).

[24] Yinger, J. (1995). Closed Doors, Opportunities Lost: The Continuing Costs of Housing Discrimination. New York: Russell Sage Foundation. 